\title{
A TEORIA DAS REPRESENTAÇÕES SOCIAIS COMO INSTRUMENTO DE COMPREENSÃO DA REALIDADE: APROXIMAÇÕES À LUZ DA EXPERIÊNCIA CONCRETA
}

\author{
The theory of social representations as an instrument for understanding reality: \\ Approaches in the light of concrete experience
}

Flávio Sacco do Anjos'

\begin{abstract}
Resumo
0 mito fundador da sociologia rural estabeleceu a oposição campo - cidade, classificando tais noções como realidades espaciais e sociais descontínuas. Tal visão reflete o efeito produzido pela teoria dicotômica que tratou de explicar o rural não por suas características intrínsecas, mas como a própria negação deste em relação ao urbano. 0 primeiro como o lugar do conservadorismo, da tradição do atraso e da estagnação, o segundo como a quintessência do dinamismo, do progresso, da modernidade. 0 rural com suas funções tradicionais (produção de alimentos, fibras e matérias-primas) e que assiste ao agônico esvaziamento demográfico e o urbano como o polo que se agiganta em meio à expansão industrial e 0 adensamento populacional. Todavia, as últimas três décadas coincidem com a emergência de novos enfoques que propugnam uma releitura do rural, reconhecendo a importância de outras vocações que pouco ou nada teriam a ver com a produção agropecuária stricto senso. Mas como estes novos papeis atribuídos ao rural são captados pelos alunos das Ciências Agrárias? Estão eles conscientes e identificados com o universo que elegeram enquanto campo de exercício profissional? A resposta a estas questões foi buscada lançando mão da teoria das representações sociais. Esse artigo tem um duplo propósito, de um lado, debater sobre essa vertente teórica e metodológica como ferramenta de pesquisa; de outro, trazer à tona uma experiência concreta sobre a qual possa ser compreendida a aplicação da teoria das representações, bem como o potencial heurístico que lhe corresponde.
\end{abstract}

Palavras-chaves: Metodologias qualitativas; Representações sociais; Rural; Ruralidades.

\begin{abstract}
The founding myth of rural sociology established the field - city opposition, classifying such notions as discontinuous spatial and social realities. Such a view reflects the effect produced by the dichotomous theory that tried to explain the rural not by its intrinsic characteristics, but as its very negation in relation to the urban. The first as the place of conservatism, the tradition of backwardness and stagnation, the second as the quintessence of dynamism, progress, modernity. The rural with its traditional functions (production of food, fibers and raw materials) and which is witnessing the agonizing demographic emptying and the urban as the pole that looms amidst industrial expansion and population density. However, the last three decades coincide with the emergence of new approaches that propose a reinterpretation of the rural, recognizing the importance of other vocations that have little or nothing to do with agricultural production in the strict sense. But how are these new roles attributed to rural people captured by students of Agrarian Sciences? Are they aware and identified with the universe they chose as a field of professional practice? The answer to these questions was sought using the theory of social
\end{abstract}

1 Programa de Pós-Graduação em Sociologia, Universidade Federal de Pelotas. E-mail: saccodosanjos@gmail.com Cidade: Pelotas/RS. 
A teoria das representações sociais como instrumento de compreensão da realidade: aproximações à luz da experiência concreta | Flávio Sacco do Anjos

representations. This article has a dual purpose, on the one hand, to debate this theoretical and methodological aspect as a research tool; on the other, to bring up a concrete experience on which the application of the theory of representations can be understood, as well as the corresponding heuristic potential.

Keywords: Qualitative methodologies; Social representations; Rural; Ruralities.

\section{Introdução}

Desde os seus albores a sociologia enfrentou diversos obstáculos para se afirmar enquanto campo do conhecimento. À guisa de introdução pode-se mencionar ao menos três. O primeiro deles é a tendência a dicotomizar individuo e sociedade como se ambos entes pudessem ser tratados de forma dissociada, quando, em verdade, são eles dimensões ou perspectivas que conformam um mesmo processo social. Tanto Pierre Bourdieu (2002) quanto Norbert Elias (1991) se ocuparam de desfazer tal equivoco em consagradas obras do pensamento sociológico. O segundo é o de superar os vícios de investigar o mundo a partir do que ele deveria ser e não o modo como se apresenta aos olhos do cientista social.

Como bem resumiu Ucrós (1970), a falta de rigor e coerência no uso de sistemas teóricos faz com que emerjam mertonianos, parsonianos, marxistas ou weberianos em lugar de sociólogos no sentido pleno da palavra. Os vícios da chamada "sociologia espontânea" são sobejamente conhecidos. Enfrentálos passa por exercer uma vigilância epistemológica que evite o contágio das noções pelas pré-noções (BOURDIEU, PASSERON e CHAMBOREDON, 1999), ou, no limite, dos conceitos pelos preconceitos.

O terceiro obstáculo, na nossa acepção, é de ordem metodológica e tem a ver com a paixão inconfessável de cientistas sociais por determinados métodos e ferramentas de pesquisa. E não estou aqui me referindo às carcomidas bases do cientificismo com sua crença dogmática que reduz todo o conhecimento ao que é mensurável ou da fé inabalável na existência de um método universal. Minha atenção se volta à incapacidade de muitos pesquisadores de experimentar novos instrumentos de investigação ou incorporar novas metodologias. 
A teoria das representações sociais como instrumento de compreensão da realidade: aproximações à luz da experiência concreta | Flávio Sacco do Anjos

É a natureza de um dado fenômeno social que deve preponderar na eleição de um determinado instrumental heurístico capaz de decodificá-lo e não o seu contrário. Decifrar a tessitura das relações, as circunstâncias e os aspectos que conspiram para o seu engendramento requer ferramentas ajustadas à singularidade do objeto. Cultivar a imaginação sociológica de que nos fala Wright Mills (1982) não passa justamente por fugir às armadilhas do método, da grande teoria e de expandir nossa percepção em relação ao mundo que nos cerca?

A teoria das representações sociais, da qual nos ocuparemos nesse artigo, é uma dentre tantas possibilidades no arsenal de metodologias qualitativas que se apresentam ao estudo de fenômenos ligados ao campo da psicologia social, da antropologia, da história e, obviamente, da sociologia. Falar sobre sua aplicação e suas virtudes pouco acrescentaria diante da profusão de estudos realizados sobre o assunto.

Minha intenção vai um pouco mais além ao trazer à reflexão uma experiência concreta de aplicação desse referencial teórico ao estudo de fenômenos sociais da contemporaneidade. O presente artigo está organizado, além dessa breve introdução, em duas outras seções. A primeira delas apresenta e discute aspectos cruciais relativos à teoria das representações sociais a partir do ponto de vista de autores proeminentes na matéria. A segunda seção foi construída dentro do esforço de exemplificar a aplicação desse recurso, mas também de evidenciar o seu potencial científico na compreensão de fenômenos sociais complexos. Algumas conclusões e considerações finais são apresentadas na terceira e última seção desse artigo.

\section{Aspectos relativos à teoria das representações sociais}

Os fatos sociais devem ser tratados como coisas, eis aí a máxima célebre concebida por Durkheim no contexto de uma obra seminal - As regras do método sociológico - que exerceu enorme influência nas ciências humanas e na própria consolidação da sociologia como disciplina e campo do conhecimento. Tratava-se de delimitar o objeto de estudo da mais jovem das ciências humanas, com seus métodos próprios e suas formas de abordagem 
A teoria das representações sociais como instrumento de compreensão da realidade: aproximações à luz da experiência concreta | Flávio Sacco do Anjos

do mundo social, os quais, contrariamente ao que muitos supunham, vão muito além do puro diletantismo e da mera especulação filosófica.

Todavia, como alude Scott (2006), Durkheim (1968) opta pelo termo representações 'coletivas' para designar fatos sociais entendidos como:

[...] crenças, ideias, valores, símbolos e perspectivas formadores dos modos de pensamento e sentimentos que são gerais e permanentes numa sociedade ou grupo social particular e que são compartilhados como sua propriedade coletiva (SCOTT, 2006, pp. 175-176).

Nesse contexto, é através do processo de socialização que os indivíduos assimilam um compromisso moral em relação ao mundo do qual fazem parte, especialmente no âmbito da família e da formação educacional. As instituições sociais são forjadas a partir do sistema de representações de uma dada coletividade ou grupo social.

Mas como advertiu Duveen (2010, p. 15), Durkheim considerava as representações coletivas como formas estáveis de compreensão das coletividades, enquanto autores contemporâneos, ligados particularmente ao campo da psicologia social, admitem tratar-se de um fenômeno social, concentrando a atenção no sentido de explorar a variação e a diversidade das ideais coletivas nas sociedades modernas.

Esse é o caso de Serge Moscovici. Segundo esse pensador romeno, radicado na França, as representações sociais não são obra da criação de individuos isolados, mas de coletividades. Entretanto, faz uma ressalva importante para o objeto do presente estudo:

A sociologia vê, ou melhor, viu as representações sociais como artificios explanatórios, irredutiveis a qualquer análise posterior. Sua função teórica era semelhante ao átomo na mecânica tradicional, ou à dos genes na genética tradicional; isto é, átomos e genes eram considerados como existentes, mas ninguém se importava com sua estrutura ou com sua dinâmica interna. A psicologia social, contudo, estaria e deveria estar pré-ocupada somente com a estrutura e a dinâmica das representações. Para nós, isso se explica na dificuldade de penetrar o interior para descobrir os mecanismos internos e a vitalidade das representações sociais o mais detalhadamente possivel

[...]. Assim, o que eu proponho fazer é considerar como um fenômeno o que era antes visto como um conceito (MOSCOVICI, 2010:45; cursivas no original). 
A teoria das representações sociais como instrumento de compreensão da realidade: aproximações à luz da experiência concreta | Flávio Sacco do Anjos

A grande contribuição de Serge Moscovici tem como ponto de partida o estudo que realizou no começo dos anos 1960, e que correspondeu à sua tese de doutoramento, através do qual, ele explora as representações sociais da psicanálise na França. Seu intuito era justamente o de entender como uma ciência, que vivia ainda o seu alvorecer, era efetivamente assimilada pelo público leigo. Em outras palavras, seu propósito era o de compreender como o saber científico adentrava na consciência dos individuos e dos grupos sociais. No limite, tratava-se de explorar o terreno das conexões entre o saber erudito e o saber ordinário.

Parte-se aqui da premissa de que as representações sociais consistem num poderoso instrumento para dar cabo das grandes questões da atualidade. Nesse sentido, coincido com Moscovici (op.cit. 48) quando este afirma que a característica específica das representações sociais é a de que elas "corporificam ideias" em experiências coletivas e interações em comportamento.

Outros autores como Jodelet (1984) são enfáticos ao afirmar que as representações sociais são produzidas pelas interações e comunicações no interior dos grupos sociais, refletindo a situação dos indivíduos no que diz respeito aos assuntos que fazem parte do seu cotidiano. Não menos importante é a posição assumida por Moscovici ao explicitar que a finalidade de toda representação é tornar familiar algo 'não-familiar'.

Nesse sentido, faço minhas as palavras de Moscovici (2010, p. 54) quando esse pondera:

O que eu quero dizer é que os universos consensuais são locais onde todos querem sentir-se em casa, a salvo de qualquer risco, atrito ou conflito. Tudo o que é dito ou feito ali apenas confirma as crenças e as interpretações adquiridas, corrobora, mais do que contradiz, a tradição.

De um modo geral as representações sociais se definem como processos ou fenômenos mentais compartilhados, através dos quais, as pessoas organizam suas vidas, fazem suas escolhas, governam suas decisões. Denise Jodelet é, em verdade, a grande herdeira do legado intelectual de Serge Moscovici. Em artigo recentemente, publicado no Brasil, ela exalta a 
A teoria das representações sociais como instrumento de compreensão da realidade: aproximações à luz da experiência concreta | Flávio Sacco do Anjos

diversidade das formas através das quais as representações sociais se manifestam. Além disso, acrescenta:

[...] mesmo que se estabeleça uma estreita relação das representações sociais com a linguagem e o discurso, mesmo que sejam tratados como prática ou força material, não constituem a única prática social a levar em consideração a abordagem da construção social dos conhecimentos e significados relativos às realidades cotidianas, bem como dos efeitos relacionados à ordem dos saberes de senso comum (JODELET, 2018, p. 433).

Os fenômenos representativos, como bem destaca Jodelet (2018, p. 436), convergem para um movimento epistemológico mais amplo, ligado ao retorno à noção do sujeito. É nesse contexto que sobressai a "interseção de três esferas de pertencimento: a esfera subjetiva, a esfera intersubjetiva, a esfera trans-subjetiva". A natureza transversal das representações sociais rompe com as armadilhas da visão disciplinar, sendo que seu poder explicativo tem sido explorado no estudo de fenômenos sociais complexos e multifacetados e baseados, sobretudo, nos discursos e narrativas dos atores sociais. A próxima seção é dedicada a refletir sobre uma experiência concreta de emprego desse arcabouço teórico e conceitual.

\section{Uma experiência concreta de aplicação da teoria das representações sociais}

Jodelet (2018), em seu estudo, menciona a guinada linguística linguist turn - operada nas ciências humanas. Convergimos no entendimento de que se trata de uma verdadeira mudança de paradigma com sua crítica pós-moderna ao modelo positivista (p. 434).

Em última análise se está diante de uma mudança metodológica importante que exalta que o trabalho conceitual dessa grande área do conhecimento não poderá ser logrado sem a devida importância à linguagem como objeto de análise. O estudo das formas de representação no seio de qualquer grupamento humano passa por indagações que Rioux e Sirinelli (1997, p. 16) concebem nos seguintes termos: Como os grupos humanos representam e como concebem o mundo ao seu redor?

Em boa medida foram estas as bases conceituais subjacentes ao estudo de caso que será aqui evocado enquanto experiência concreta destinada a ilustrar a aplicação da teoria das representações sociais. A base empírica construída foi resultante do uso de um conjunto de técnicas que 
A teoria das representações sociais como instrumento de compreensão da realidade: aproximações à luz da experiência concreta | Flávio Sacco do Anjos

serão posteriormente descritas. Trata-se do estudo de representações sociais do rural a partir da perspectiva de estudantes de Ciências Agrárias de uma consagrada instituição federal de ensino superior, qual seja, a Faculdade de Agronomia Eliseu Maciel, fundada em 1883, em pleno regime imperial do Brasil.

\title{
3.I Representações do rural entre estudantes de Ciências Agrárias
}

O antagonismo campo-cidade está inscrito nas bases fundacionais da Sociologia Rural, um ramo especializado da sociologia geral que nasce no interior dos Land Grant Colleges dos EUA no final do século XIX e que, durante as cinco primeiras décadas do século XX, chega ao seu apogeu como a mais importante disciplina acadêmica da ciência social estadunidense. Conforme Howard Newby (1982), esta sociologia rural que "se inventou", segundo suas próprias palavras, no interior das escolas de agronomia estadunidenses e se espalhou rapidamente pelo mundo, se caracterizava por um determinado estilo de pesquisa que deveria ser visto com muito ceticismo. Além disso, acrescenta:

\begin{abstract}
Las características de este estilo "científico" son las siguientes: positivista, inductivo, cuantitativo y " aplicado". Es un estilo que define el campo de la sociología rural no menos que su temática, un producto de la "hegemonía paradigmática", del "enclaustramiento teórico" y del "monismo metodológico" de la sociología rural (NEWBY, 1982, p. 349; destacado no original).
\end{abstract}

Do ponto de vista teórico, suas bases fundantes estão enraizadas no enfoque dicotômico de Sorokin, Zimmerman \& Galpin (1986). Dentro desse marco, o rural não por suas características intrínsecas, mas como a própria negação do urbano. De um lado, o urbano, referente máximo de um mundo dinâmico, industrial e pujante que se expandia horizontal e verticalmente como lócus privilegiado da vida moderna. Enquanto isso, as áreas rurais e os espaços não densamente urbanizados sangravam demograficamente e definhavam culturalmente.

O mundo rural era admitido como expressão do polo tradicional, conservador, arcaico, desprovido de relevância e relegado à missão exclusiva de produzir fibras, matérias-primas e alimentos para atender as necessidades 
A teoria das representações sociais como instrumento de compreensão da realidade: aproximações à luz da experiência concreta | Flávio Sacco do Anjos

de cidades que se agigantavam do dia para a noite. Já as pequenas localidades assistiam e seguem assistindo inertes a sua própria agonia.

O projeto de modernização agrária levado a termo nos países do III Mundo, incluindo obviamente o Brasil, replicaram à "raja tabla" esse desiderato. O espaço que disponho nesse artigo me impede ampliar essa discussão, a qual cobra enorme importância dentro das ciências humanas. Nesse sentido, Martins traduziu de forma magistral a importância assumida por uma disciplina acadêmica - a sociologia rural - colocada a serviço de um projeto levado a cabo no Brasil, cujo auge coincide com a ditadura militar (1964-1985). Segundo suas próprias palavras,

Quando assumiu o mundo rural como objeto, a sociologia rural o fez mais como "adversária" do que como ciência isenta e neutra. Mais como ciência da modernização do que como ciência aberta à compreensão dos efeitos destrutivos e perversos que não raro a modernização acarreta. A modernização é um valor dos sociólogos rurais e não necessariamente das populações rurais, porque, de fato, para estas não raro ela tem representado desemprego, desenraizamento, desagregação da família e da comunidade, dor e sofrimento (MARTINS, 2001, p. 32; aspas no original).

Outros autores foram igualmente duros em suas críticas aos pecados originais da sociologia rural estadunidense, com suas vinculações explícitas a um projeto de modernização centrado na vulgarização das inovações tecnológicas. Todavia, talvez nenhum deles tenha sido tão enfático quanto Hightower, autor resgatado por Newby (1982, p. 350) cuja desaprovação é apresentada nos seguintes termos:

Jim Hightower destaca tales debilidades en su obra Hard Tomatoes, Hard Times, que constituye un fuerte e interesado ataque contra el complejo LG $^{2}$ de Estados Unidos, al que acusa de ser un cliente obsequioso de las grandes agroempresas. Hightower no se anduvo con rodeos. En su opinión, "el grueso de la investigación de sociología rural" constituye " mierda sociológica" (destaques no original).

Para os jovens que ingressam nos cursos de ciências agrárias (Agronomia, Veterinária, Engenharia Agrícola e Zootecnia) de uma tradicional instituição de ensino superior brasileira está mais que enraizada a vocação precipua dos espaços rurais. Direta ou indiretamente é no âmbito das cadeias de produção animal e vegetal que boa parte os estudantes egressos desses cursos anseiam se inserir. Vislumbram atuar como agentes cuja formação

\footnotetext{
${ }^{2}$ Land Grant Colleges.
} 
A teoria das representações sociais como instrumento de compreensão da realidade: aproximações à luz da experiência concreta | Flávio Sacco do Anjos

técnica, no seio de nossas universidades, foi invariavelmente concebida à imagem e semelhança do paradigma produtivista aludido anteriormente. " $\mathrm{O}$ agro é tech, o agro é pop, o agro é tudo" era o mote de uma milionária campanha publicitária levada a efeito pela maior rede de televisão do Brasil durante os últimos anos (2015-2018) para enaltecer as supostas virtudes e a pujança do setor agroexportador nacional.

Mas o mundo rural que se descortina desde a segunda metade dos anos 1990 vai muito além dessas funções tradicionais a ele atribuídas, tanto que já não se fala mais do rural (no singular), senão de ruralidades (CARNEIRO e TEIXEIRA, 2012), aduzindo as múltiplas funções que passa a incorporar, entre as quais figuram em destaque o de converter-se em espaço de ócio e entretenimento, incluindo as mais diversas modalidades de turismo (de aventura, rotas enogastronômicas, culturais e ecológicas, apenas por citar alguns exemplos). Mas o rural é também o espaço da biodiversidade e o lugar onde pulula a vida natural, sendo o reduto de várias espécies de animais silvestres ameaçadas de extinção.

O reconhecimento do status dessa nova ruralidade (WANDERLEY, 2001) representa um ponto de inflexão importante nos estudos sobre a realidade brasileira. Decididamente o rural não mais pode ser assumido como sinônimo de agrário. Esse foi o argumento basal de um programa de investigação (Projeto Rurbano) levado a efeito em todas as grandes regiões do Brasil, mostrando que existe uma proporção crescente de famílias, denominadas 'pluriativas' (ANJOS, 2003; CARNEIRO, 1998; DEL GROSSI e GRAZIANO DA SILVA, 1998), que apesar de residirem no campo, não vivem mais exclusivamente das atividades agropecuárias, senão do exercício de múltiplos ofícios e labores que nada, ou muito pouco, têm a ver com a agricultura stricto senso.

Entrementes, que pensam os jovens que hodiernamente afluem aos cursos de Ciências Agrárias? Estão eles impregnados da força dessas novas funções atribuídas aos espaços rurais ou seguem aferrados à tradicional vocação referida anteriormente e alardeada aos quatro ventos pelos próceres do agronegócio exportador e pelas lideranças do empedernido agrarismo dos 
A teoria das representações sociais como instrumento de compreensão da realidade: aproximações à luz da experiência concreta | Flávio Sacco do Anjos

sindicatos e corporações do setor agropecuário nacional? Antes de buscar respostas a estas questões, cabe esclarecer a metodologia que marcou a realização desse estudo.

\section{I.I Metodologia empregada na pesquisa}

As grandes questões aludidas no parágrafo anterior guiaram o levantamento de um conjunto de dados informações junto a totalidade dos alunos regularmente matriculados, no ano letivo 2016 nos cursos de Agronomia (47), Veterinária (46) e Zootecnia (19), enquanto participantes de uma disciplina obrigatória (Extensão Rural) ministrada sempre nos últimos semestres dos três cursos mencionados.

O itinerário metodológico da pesquisa se subdivide em três momentos. No primeiro deles, os alunos elaboraram, através do recurso fotográfico, e, segundo suas respectivas preferências, uma imagem de rural que considerassem mais representativa, refletindo a sua própria acepção ou conceito. Paralelamente deveriam redigir, por escrito, uma narrativa da própria foto, explicando as razões ou justificativas para a imagem ou cenário escolhido.

Posteriormente houve a realização de uma aula especial em que as imagens digitalizadas das fotos foram apresentadas ao grande grupo, bem como a descrição e comentário ou relato verbal da fotografia por cada um dos alunos participantes. No final do semestre houve uma exposição do registro fotográfico de todos os alunos participantes no saguão da universidade. $O$ objetivo principal foi divulgar a iniciativa, valorizando o esforço envidado pelos discentes, bem como dar a conhecer as diferentes visões em relação ao mundo rural.

O segundo momento da pesquisa envolveu uma dinâmica grupal em que cada aluno deveria indicar uma palavra ou expressão que considerasse mais representativa do que vem a ser o rural. Encontramo-nos diante de um conceito que se mostra umbilicalmente atrelado a um espaço geográfico e social singular, mas também ao campo de atuação futura daqueles que estão às vésperas de deixarem a universidade para, assim, encararem os desafios da vida profissional. 
A teoria das representações sociais como instrumento de compreensão da realidade: aproximações à luz da experiência concreta | Flávio Sacco do Anjos

Nesse mesmo encontro os discentes preencheram um questionário com perguntas fechadas e abertas (doze no total) cujo objetivo central era obter informações sobre a origem social, os vínculos objetivos e subjetivos com o rural, mas também com as atividades agropecuárias. As representações sociais sobre o rural foram construídas, operacionalmente, a partir da aplicação destas técnicas e recursos metodológicos.

3.2 As representações sociais do rural entre estudantes de Ciências Agrárias

Os dados indicam (Tabela $n^{\circ}$ ) que $74,1 \%$ dos estudantes têm idade inferior a 25 anos e que apenas 6,3\% deles superavam os trinta anos de idade no momento da pesquisa, mostrando um perfil bastante jovem. Já os dados da Tabela $n^{\circ} 2$ revelam que uma proporção bastante alta dos discentes nasceu no Rio Grande do Sul, estado situado no extremo meridional do Brasil.

O conjunto de alunos se acha rigorosamente dividido entre os gêneros feminino (50\%) e masculino (50\%). Entrementes, quando se analisa os cursos separadamente (Tabela $\mathrm{n}^{\circ}$ 3) há diferenças dignas de nota. O curso de Zootecnia é o que apresenta a maior proporção de mulheres $(68,4 \%)$, seguido de perto pela Veterinária (65,2\%). Já na Agronomia a participação de mulheres é consideravelmente mais baixa $(27,7 \%)$. A presença feminina em espaços até bem pouco tempo dominados pelos homens reveste importância, tratando-se de fenômeno que desvela uma revolução silenciosa operada no país e no mundo, de uma forma geral, nas quatro últimas décadas.

Tabela 1. Distribuição do conjunto de estudantes investigados segundo intervalos de idade.

\begin{tabular}{lrr}
\hline Faixa etária (anos) & Frequência & \multicolumn{1}{c}{$\%$} \\
\hline Até 22 & 37 & 33,0 \\
23 a 25 & 46 & 41,1 \\
26 a 30 & 21 & 18,8 \\
31 e acima & 7 & 6,3 \\
Sem informação & 1 &, 9 \\
\hline \multicolumn{3}{c}{ Total } \\
\multicolumn{3}{c}{ Fonte: Pesquisa de campo (2016). }
\end{tabular}


A teoria das representações sociais como instrumento de compreensão da realidade: aproximações à luz da experiência concreta | Flávio Sacco do Anjos

Tabela 2. Distribuição dos discentes entrevistados segundo a unidade federativa de nascimento.

\begin{tabular}{|c|c|c|}
\hline Unidade Federativa & Frequência & Percentual \\
\hline Rio Grande do Sul & 101 & 90,2 \\
\hline São Paulo & 06 & 5,4 \\
\hline Santa Catarina & 04 & 3,6 \\
\hline Piauí & 01 & 0,8 \\
\hline Total & 112 & 100.0 \\
\hline
\end{tabular}

Tabela 3. Distribuição dos estudantes entrevistados segundo gênero e respectivo curso frequentado

\begin{tabular}{lcc}
\hline \multirow{2}{*}{ Curso } & \multicolumn{2}{c}{ Proporção de gênero (\%) } \\
& Masculino & Feminino \\
\hline Agronomia & 72,3 & 27,7 \\
Veterinária & 34,8 & 65,2 \\
Zootecnia & 31,6 & 68,4 \\
\hline Total & 50,0 & 50,0 \\
\hline \multicolumn{2}{c}{ Fonte: Pesquisa de campo (2016). }
\end{tabular}

Nesse sentido, estudo realizado por Guedes mostra que em 1970 as mulheres representavam, respectivamente, apenas 3\% e 4\% dos agrônomos e veterinários formados no Brasil. Mas nos anos 2000 essa participação sobe para $12 \%$ no caso da Agronomia e a $30 \%$ no caso da Veterinária (GUEDES, 2008, p. 126). Ainda assim, segundo a mesma fonte, quando se cruza esse dado com a questão da idade, o protagonismo feminino se amplia sensivelmente.

Assim, na faixa etária dos 20 a 29 anos as agrônomas e veterinárias representam 23\% e 50\%, respectivamente, muito acima do que se constata em termos gerais. Os dados aqui reunidos só fazem confirmar que essa tendência não somente se manteve, mas inclusive se fortalece na última década. No caso da Veterinária há que sopesar o fato de que muitos dos jovens optam por esse curso para dedicarem-se aos cuidados de pequenos animais (clinicas e pet shops) e, não necessariamente, às atividades agropecuárias propriamente ditas.

O espaço da produção animal (equinos, bovinos, ovinos, suínos) que anteriormente era de domínio do curso de Veterinária vem sendo ocupado pelo curso de Zootecnia, o qual, como aqui ficou demonstrado, espelha a forte 
A teoria das representações sociais como instrumento de compreensão da realidade: aproximações à luz da experiência concreta | Flávio Sacco do Anjos

presença do gênero feminino. Estas jovens encaram um mundo onde o machismo não pode ser visto como algo insignificante na dinâmica de pequenas, médias e grandes fazendas de produção animal, bem como nas empresas ligadas às grandes cadeias do setor agropecuário.

Cabe agora examinar outros aspectos que interessa sublinhar para delimitar o campo de observação dessa investigação. Nesse contexto, a pesquisa em tela mostrou que apenas 35\% dos entrevistados se declaram como sendo de origem rural. Esse dado é consoante com a informação relativa à residência dos progenitores (Tabela $n^{\circ} 4$ ), mostrando que o domicílio rural foi indicado para $36 \%$ no caso do pai e de $25,9 \%$ no caso da mãe dos alunos.

Tabela 4. Situação de domicílio ou residência do pai e da mãe dos estudantes entrevistados.

\begin{tabular}{cc}
\hline & Residência rural (\%) \\
\hline Pai do estudante & 36,0 \\
Mãe do estudante & 25,9 \\
\hline Fonte: Pesquisa de campo (2016).
\end{tabular}

Partiu-se do suposto de que as representações sociais dos jovens acerca do rural são influenciadas por diversos fatores. Isso fez com que se buscasse explorar outros elementos que pudessem influenciar as escolhas, como no caso da profissão ou ocupação exercida pelos pais.

No caso do progenitor foram contabilizadas nada menos que 42 profissões ou oficios diferentes, ainda que a mais expressiva delas corresponda a de 'produtor rural' (25,9\%). No caso das mães a diversidade de profissões elencadas é menor (33 tipos de ofícios distintos), com destaque para a condição de dona de casa $(22,3 \%)$, professora $(14,3 \%)$, sendo que apenas $9,8 \%$ foram declaradas como 'produtora rural'.

Um dos tópicos que despertava interesse elucidar era justamente o de aprofundar essa ligação real ou idealizada do estudantado com o rural. Quando perguntados se possuíam algum vínculo com o rural, 75\% responderam afirmativamente e $25 \%$ negativamente. Do grupo que revelou a ausência total de vínculos com o rural, 75\% pertencem ao curso de veterinária, situação que decorre do fato de ser este o subgrupo constituído 
A teoria das representações sociais como instrumento de compreensão da realidade: aproximações à luz da experiência concreta | Flávio Sacco do Anjos

por aqueles que futuramente irão se dedicar ao cuidado de pequenos animais (clinicas e pet shops).

Não obstante, essa suposta ligação foi tomada na pesquisa como um ponto de partida no sentido de explorar os meandros da questão. Com efeito, ao se examinar a narrativa construída pelos entrevistados, percebem-se laços objetivos com o rural, como no caso de pais que são produtores, assentados da reforma agrária, técnicos agrícolas, trabalhadores do campo. Não obstante, constam também vínculos que são muito frágeis e claramente subjetivos.

Muitos dos que informaram tal ligação com o rural são filhos de profissionais liberais (advogados, dentistas, médicos, etc.) residentes na cidade, os quais possuem estabelecimentos rurais explorados mediante contratos de arrendamento firmados com terceiros. Essa vinculação dá-se, portanto, de forma bastante indireta, parcial ou difusa.

As respostas dos estudantes demandam a análise dessa vinculação com o rural fazendo uso de outros pontos de vista, como no caso da condição de residência e profissão dos pais, se a família é proprietária de estabelecimento rural e se vive integral ou parcialmente da renda auferida através do exercício de atividades agropecuárias. Nesse caso, a ênfase se orienta para aquela que é considerada como a vocação precípua (produção animal e vegetal), mas, obviamente, não exclusiva, dos espaços rurais.

Com base nestes critérios, a vinculação com o rural foi mensurada segundo quatro niveis ou escalas (forte, médio, fraca e nenhum vínculo). No primeiro caso, trata-se de jovens cujos pais vivem da agricultura ou são agricultores e/ou criadores, residem no meio rural ou no próprio estabelecimento agropecuário. Já no caso do nível médio tais critérios são atendidos apenas parcialmente, enquanto no nível fraco esse atendimento é mínimo ou inexistente.

No último nivel (nenhum vínculo) os alunos afirmaram categoricamente não possuir qualquer tipo de vínculo ou ligação com o meio rural. Os dados Tabela $\mathrm{n}^{\circ} 5$ mostram que apesar de aproximadamente $75 \%$ dos estudantes haverem indicado algum tipo de vinculação com o rural, na verdade, em apenas $29,5 \%$ dos casos, estamos diante de uma ligação efetiva ou forte. 
A teoria das representações sociais como instrumento de compreensão da realidade: aproximações à luz da experiência concreta | Flávio Sacco do Anjos

A ligação é fraca e inexistente para respectivamente $32,1 \%$ e $26,8 \%$ dos alunos de ciências agrárias em geral. Quando a análise é feita por faculdade, verifica-se que o nível de vinculação forte para estudantes do curso de Agronomia alcança 53,2\% do universo, enquanto para o caso da Zootecnia e Veterinária atinge, respectivamente, $26,3 \%$ e $6,5 \%$.

Tabela 5. Distribuição dos estudantes entrevistados segundo o nível de vinculação com o rural.

\begin{tabular}{lc}
\hline Nível de vinculação & Percentual (\%) \\
\hline Forte & 29,5 \\
Médio & 11,6 \\
Fraco & 32,1 \\
Nenhum & 26,8 \\
\hline Total & 100,00 \\
\hline \multicolumn{2}{c}{ Fonte: Pesquisa de campo (2016). }
\end{tabular}

$\mathrm{Na}$ sessão em que as fotos foram apresentadas e onde teve lugar a exposição das razões e motivos que guiaram a escolha da imagem representativa do rural, pediu-se aos estudantes que elegessem uma palavra ou expressão que, no seu entendimento, pudesse sintetizar a respectiva ideia de rural. Na realização dessa dinâmica insistiu-se no fato de que não se tratava de saber o que poderia ser certo ou errado. Eleger livremente a palavra era parte de um exercício que expunha um sistema de preferências, uma opinião pessoal e a influência da trajetória pessoal de cada um dos participantes na sua respectiva escolha.

A nuvem de palavras (Figura $n^{\circ} 1$ ) mostra a recorrência das escolhas dos alunos, os quais indicaram 52 palavras distintas para expressar sua ideia de rural. De longe sobressai o rural ligado ao conceito de campo, de trabalho, de produção, de diversidade, de vida, natureza e ocupação, mas também de um espaço de tranquilidade, pureza e simplicidade.

Mas quando se examina minuciosamente os dados reunidos nessa etapa da pesquisa, constatou-se a existência de três famílias de palavras ou de categorias de rural. Nesse contexto, as representações sociais do rural do alunado se apresentam estruturadas em três grandes eixos conceituais. $\mathrm{O}$ primeiro deles é o que podemos denominar como "rural agropecuário", refletindo escolhas que remetem ao âmbito da produção e do trabalho agrícola. 
A teoria das representações sociais como instrumento de compreensão da realidade: aproximações à luz da experiência concreta | Flávio Sacco do Anjos

O segundo eixo remete ao que consideramos como o "rural idílico". Nesse caso, tem-se as associações feitas ao rural como lugar da memória, traduzindo-se numa conexão de caráter sentimental ou afetivo com esse espaço. A terceira concepção compreende o chamado rural "ecológico ou ambiental", pressupondo uma versão mais ligada ao lugar da natureza e da biodiversidade, das plantas e dos animais silvestres.

Figura 1. Nuvem de palavras construída a partir de indicação livre (escolha) dos estudantes de agrárias sobre o que entendem por rural

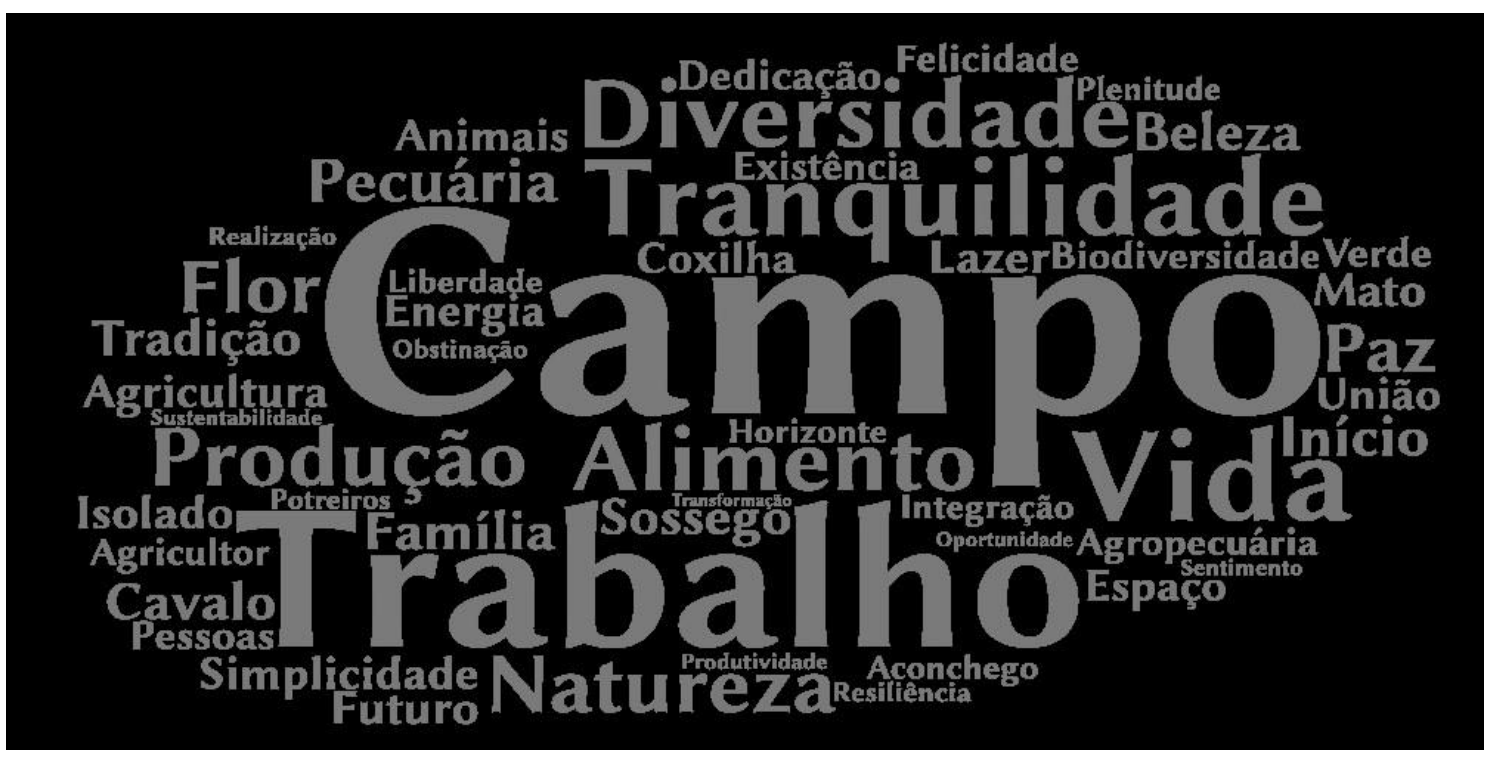

Fonte: Pesquisa de campo (2016).

Apesar da origem dos estudantes de Agrárias estar cada vez menos relacionada com as atividades agropecuárias, a concepção do rural agropecuário se impõe sobre as demais e pode ser traduzida em depoimentos tais como:

- Minha família possui uma propriedade, na qual nós produzimos soja, arroz e pecuária

- Resido no meio rural e minha família se sustenta da renda da comercialização da soja e arroz produzidos.

- Meus pais são oriundos do meio rural, trabalham em uma propriedade no interior do município, no $2^{\circ}$ distrito.

O rural idílico é aquele que povoa o imaginário de jovens que vislumbram um lugar regido por um sistema de valores pautado em relações diretas e pessoais. Além disso, um ambiente visto como refúgio e onde impera 
A teoria das representações sociais como instrumento de compreensão da realidade: aproximações à luz da experiência concreta | Flávio Sacco do Anjos

um sistema de valores marcado pela solidariedade, franqueza, pureza e sinceridade das pessoas que ali vivem.

Retratam eles um universo sociocultural mediado pelos ritmos da natureza e onde habita a tranquilidade e simplicidade. Essa espécie de "sacralização" do rural impera nas falas, nas fotografias e nos vocábulos elegidos pelos jovens entrevistados, os quais, em grande medida, nasceram, ou vivem atualmente na cidade, possuindo, portanto, uma origem eminentemente urbana:

- Durante a infância eu passava os dias na campanha.

- Fui criada no campo de meus avós, em Herval. Além disso, atualmente, convivo com meu namorado na cabanha da família dele.

- Meu pai e seus irmãos sempre trabalharam produzindo arroz irrigado em Santa Vitória. Tive contato, porém, de longe, por exemplo, nas férias e finais de semana.

- Meus avós maternos nasceram e se criaram em fazendas no interior de São Paulo, assim como meu avô paterno.

Resta saber, no reduzido espaço que aqui disponho, como se apresentam efetivamente as três concepções de rural do ponto de vista das preferências dos alunos com os quais a pesquisa foi realizada. As respostas foram organizadas a partir das indicações de vocábulos feitas livremente pelos alunos e pelo emprego das técnicas referidas anteriormente.

Através da Tabela $n^{\circ} 6$ é possivel constatar que o rural agropecuário prepondera com $44,6 \%$ das preferências. Já o rural idílico ou idealizado abarca 38,4\% das preferências dos respondentes, seguido de longe por 17,0\% dos discentes cujas representações sociais se orientam por uma acepção de tipo ecológico-ambiental.

Tabela 6. Distribuição das palavras que definem o rural segundo categorias ou famílias.

\begin{tabular}{lrr}
\hline Categoria de Rural & Frequência & Percentual \\
\hline Agropecuário & 50 & 44,6 \\
Idílico & 43 & 38,4 \\
Ecológico-Ambiental & 19 & 17,0 \\
\hline Total & 112 & 100,0 \\
\hline \multicolumn{2}{c}{ Fonte: Pesquisa de campo (2016). }
\end{tabular}

Apesar de minoritária, a acepção ecológica ou ambiental denota a percepção sobre a existência de outras funções atribuídas ao rural, inclusive 
A teoria das representações sociais como instrumento de compreensão da realidade: aproximações à luz da experiência concreta | Flávio Sacco do Anjos

aquelas mais ligadas à fruição ou ao deleite da paisagem natural. Nas falas desse grupo de entrevistados a questão da preservação e dos imperativos da sustentabilidade não goza da importância esperada, fato que demanda estudos ulteriores.

Possivelmente, se tal aproximação houvesse sido feita junto a estudantes oriundos de outros campos do conhecimento (ecologia, ciência ambiental, biologia, etc.) a acepção ecológico-ambiental do rural ganharia um maior peso específico.

Por fim, os dados da Tabela 7 foram concebidos no sentido de verificar se existiam diferenças nas respostas definidoras do rural entre os gêneros. Percebe-se que a concepção de 'rural agropecuário' prepondera entre os rapazes $(48,2 \%)$ em relação às moças $(41,1 \%)$. Não obstante, a acepção do 'rural idílico' supera no caso das moças $(46,4 \%)$ em relação aos rapazes $(30,4 \%)$. Todavia, não há elementos que permitam tirar maiores conclusões.

Tabela 7. Distribuição das palavras definidoras do rural segundo categorias e gênero dos respondentes.

\begin{tabular}{|c|c|c|c|c|}
\hline \multirow[t]{2}{*}{ Gênero } & \multicolumn{3}{|c|}{$\begin{array}{c}\text { Distribuição percentual das palavras, } \\
\text { segundo a categoria de rural }\end{array}$} & \multirow[t]{2}{*}{ Total } \\
\hline & Agropecuário & Ecológico & Idílico & \\
\hline Masculino & 48,2 & 21,4 & 30,4 & 100,0 \\
\hline Feminino & 41,1 & 12,5 & 46,4 & 100,0 \\
\hline
\end{tabular}

\section{Considerações finais}

A teoria das representações sociais ocupa um lugar de destaque dentro do elenco de metodologias de natureza qualitativa empregadas nas pesquisas sociológicas. O grande artífice da redescoberta foi Moscovici com seus estudos voltados ao campo da psicologia social. Destarte, suas raízes se assentam no interior daquela que é considerada a obra magistral de Ėmile Durkheim (As regras do método sociológico).

Manifestações de todo gênero, "não apenas verbais, discursivas, mas também icônicas, comportamentais, gestuais, rituais, rotineiras, práticas ou ainda artísticas" (JODELET, 2018) emolduram o cerne onde opera o universo das representações sociais. Em outra passagem da citada obra, Jodelet traz à 
A teoria das representações sociais como instrumento de compreensão da realidade: aproximações à luz da experiência concreta | Flávio Sacco do Anjos

tona o exemplo do estudo de representações sociais da loucura numa comunidade rural francesa na qual os pacientes portadores de transtornos psíquicos foram alojados. Como bem ressalta esta autora,

\begin{abstract}
[...] as práticas reservadas ao cuidado de seus corpos e de seus pertences pessoais revelaram a existência de uma crença de contágio da loucura por meio do contato com fluidos corporais, baseado em antiga representação do funcionamento corporal e mental. Essa crença permitiu que fosse assegurado o afastamento social dos doentes (JODELET, 2018, p. 434).
\end{abstract}

Em última instância, as representações sociais governam escolhas e guiam decisões dos atores sociais em seu devenir histórico. Nesse artigo minha intenção perseguiu dois grandes objetivos. O primeiro deles foi no sentido de mostrar a importância heurística dessa ferramenta para a pesquisa sociológica, mas também para outros campos do conhecimento.

O segundo objetivo foi no afã de explicitar uma situação concreta em que a teoria das representações sociais oferece uma chave de compreensão às formas através dos quais os atores sociais constroem uma visão de mundo sobre questões que lhes afetam diretamente. Entre as lições deixadas por Moscovici consta que as representações sociais convencionalizam os objetos, pessoas ou acontecimentos.

Além disso, elas “[...] são prescritivas, isto é, elas se impõem sobre nós com uma força irresistivel. Essa força é uma combinação de uma estrutura que está presente antes mesmo que nós comecemos a pensar e de uma tradição que decreta o que deve ser pensado" (MOSCOVICI, 2010, p. 36; cursivas no original).

O caso em tela trouxe à tona as representações sociais do rural a partir da perspectiva de estudantes de fim de curso da área das Ciências Agrárias. Longe se está de uma expressão única e monolitica dessa questão vista aqui como um fenômeno sujeito ao crivo da reflexão científica. Três grandes categorias de rural (agropecuário, idílico e ecológico ambiental) emergiram na aproximação realizada nessa pesquisa.

A primeira delas é a que se atem ao mundo da produção, a segunda mais centrada numa relação atávico-afetiva enquanto a terceira identifica o rural como lócus privilegiado da biodiversidade. Conforme assinalou 
A teoria das representações sociais como instrumento de compreensão da realidade: aproximações à luz da experiência concreta | Flávio Sacco do Anjos

Moscovici (2010, p. 41) as representações sociais são criadas, adquirindo vida própria. Esse processo não impede o surgimento de novas representações sociais enquanto simultaneamente fenecem velhas representações.

\section{Agradecimentos}

Este artigo foi concebido durante minha estância como Professor Visitante Sênior junto ao "Instituto de Estudios Sociales Avanzados", ligado ao "Consejo Superior de Investigaciones Científicas” de Espanha (IESA-CSIC), entre os meses de setembro de 2019 e agosto de 2020. Agradeço a acolhida dos colegas do IESA-CSIC (Córdoba), bem como à Coordenação de Aperfeiçoamento de Pessoal de Nivel Superior (CAPES) pela concessão de Bolsa de Professor Visitante Sênior no marco do Programa Institucional de Internacionalização (PRINT-CAPES) (processo $\left.n^{\circ} 88887.363956 / 2019-00\right)$. Registro, outrossim, minha gratidão ao Conselho Nacional de Desenvolvimento Científico e Tecnológico (CNPq) pela concessão de produtividade (processo $n^{\circ} 305086 / 2018-9$ ).

\section{Referências:}

ANJOS, Flávio Sacco dos. Agricultura familiar, pluriatividade e desenvolvimento rural no Sul do Brasil. Pelotas: EGUFPEL. 2003.

BOURDIEU, Pierre; CHAMBOREDON, Jean-Claude; PASSERON, JeanClaude. El Oficio del Sociólogo. México, Siglo XXI, 1999.

BOURDIEU, Pierre. Lección sobre la lección, Barcelona, Anagrama, 2002.

CARNEIRO, Maria José; TEIXEIRA, Vanessa Lopes. Para além das dualidades. In: CARNEIRO, Maria José (Org.). Ruralidades Contemporâneas. Modos de viver e pensar o rural na sociedade brasileira. Rio de Janeiro: Mauad, 2012.

CARNEIRO, Maria José. Camponeses, agricultores e pluriatividade. Rio de Janeiro: Contra Capa. 1998.

DEL GROSSI, Mauro; GRAZIANO DA SILVA, José. A pluriatividade na agropecuária brasileira em 1995. Estudos Sociedade e Agricultura, v.11, 1998.

DURKHEIM, Ėmile. As regras do método sociológico, 5a. ed., São Paulo: Editora Nacional. 1968. 
A teoria das representações sociais como instrumento de compreensão da realidade: aproximações à luz da experiência concreta | Flávio Sacco do Anjos

DUVEEN, Gerard. Poder das Ideias. In: MOSCOVICI, Serge. (Ed.), Representações sociais. Investigações em psicologia social, Petrópolis: Editora Vozes, 2010.

ELIAS, Norbert. The Society of Individuals, Oxford, Basil Blackwell, 1991.

GUEDES, Moema de Castro. A presença feminina nos cursos universitários e nas pós-graduações: desconstruindo a ideia da universidade como espaço masculino. História Ciências Saúde- Manguinhos, v. 15, 2008.

JODELET. Denise. Ciências sociais e representações: estudo dos fenômenos representativos e processos sociais, do local ao global. Sociedade e Estado, v.33, n $2,2018$.

JODELET, Denise. La representación social: fenómenos, conceptos y teoría. In: MOSCOVICI, Serge. Psicologia social II. Pensamiento y vida social. Psicología social y problemas sociales. Barcelona-Buenos Aires-México: Paidós, 1984.

MARTINS, José de Souza. O futuro da sociologia rural e sua contribuição para a qualidade de vida rural. Estudos Avançados, v.15, n 43, 2001.

MOSCOVICI, Serge. Representações sociais. Investigações em psicologia social. $7^{\mathrm{a}}$ Ed Petrópolis: Editora Vozes, 2010.

NEWBY, Howard. El desafio de la sociologia rural. Comercio Exterior, v. 32, $\mathrm{n}^{\circ} 4,1982$.

RIOUX, Jean Pierre; SIRINELLI, Jean-François. Pour une histoire culturelle. Paris: Les Éditions du Seuil, 1997.

SCOTT, John. Sociologia: conceitos-chave. Rio de Janeiro: Zahar, 2006.

SOROKIN, Pitirin; ZIMMERMAN, Carle; GALPIN, Charles. Diferenças fundamentais entre o mundo rural e o mundo urbano. In MARTINS, José de Souza. Introdução crítica à sociologia rural. São Paulo: Hucitec, 1986.

UCRÓS, Jorge. Algunos problemas metodológicos en sociología, Revista Mexicana de Sociologia, v.31, $n^{\circ} 5,1970$.

WANDERLEY, Maria Nazaré. Baudel. A emergência de uma nova ruralidade nas sociedades modernas avançadas. Estudos Sociedade e Agricultura, v.15, 2001.

WRIGHT MILLS, Charles. A Imaginação Sociológica, Rio de Janeiro. Zahar, 1982. 